\title{
Fecal prevalence, serotype distribution and antimicrobial resistance of Salmonellae in dairy cattle in central Ethiopia
}

\author{
Tadesse Eguale ${ }^{1 *}$, Ephrem Engidawork ${ }^{2}$, Wondwossen A. Gebreyes ${ }^{3}$, Daniel Asrat ${ }^{4}$, Haile Alemayehu',
} Girmay Medhin ${ }^{1}$, Roger P. Johnson ${ }^{5}$ and John S. Gunn ${ }^{6}$

\begin{abstract}
Background: Salmonellae are major worldwide zoonotic pathogens infecting a wide range of vertebrate species including humans. Consumption of contaminated dairy products and contact with dairy cattle represent a common source of non-typhoidal Salmonella infection in humans. Despite a large number of small-scale dairy farms in Addis Ababa and its surrounding districts, little is known about the status of Salmonella in these farms.

Results: Salmonella was recovered from the feces of at least one animal in $7.6 \%$ (10/132) of the dairy farms. Out of 1203 fecal samples examined, 30 were positive for Salmonella resulting in a weighted animal level prevalence of $2.3 \%$. Detection of diarrhea in an animal and in a farm was significantly associated with animal level $(p=0.012)$ and herd level $(p<0.001)$ prevalence of Salmonella. Animal level prevalence of Salmonella was significantly associated with age ( $p=0.023)$ and study location; it was highest among those under 6 months of age and in farms from Adaa district and Addis Ababa $(p<0.001)$. Nine different serotypes were identified using standard serological agglutination tests. The most frequently recovered serotypes were Salmonella Typhimurium (23.3\%), S. Saintpaul (20\%), S. Kentucky (16.7 \%) and S. Virchow (16.7\%). All isolates were resistant or intermediately resistant to at least one of the 18 drugs tested. Twenty-six (86.7\%), 19 (63.3\%), 18 (60\%), 16 (53.3\%) of the isolates were resistant to streptomycin, nitrofurantoin, sulfisoxazole and tetracycline, respectively. Resistance to 2 drugs was detected in $27(90 \%)$ of the isolates. Resistance to 3 or more drugs was detected in 21 (70 \%) of the isolates, while resistance to 7 or more drugs was detected in 11 (36.7 \%) of the isolates. The rate of occurrence of multi-drug resistance (MDR) in Salmonella strains isolated from dairy farms in Addis Ababa was significantly higher than those isolated from farms outside of Addis Ababa ( $p=0.009)$. MDR was more common in S. Kentucky, S. Virchow and S. Saintpaul.
\end{abstract}

Conclusion: Isolation of Salmonella serotypes commonly known for causing human salmonellosis that are associated with an MDR phenotype in dairy farms in close proximity with human population is a major public health concern. These findings imply the need for a strict pathogen reduction strategy.

Keywords: Dairy farm, Feces, Salmonella enterica, Multi-drug resistance

\section{Background}

Salmonella is a diverse bacterial species comprising over 2600 serotypes [1]. Salmonella commonly colonizes a range of animal hosts such as mammals, amphibians, reptiles, birds and insects [2]. There are 2 species of Salmonella: Salmonella enterica and Salmonella bongori.

\footnotetext{
* Correspondence: tadesse.eguale@aau.edu.et

${ }^{1}$ Aklilu Lemma Institute of Pathobiology, Addis Ababa University, P.O. Box

1176, Addis Ababa, Ethiopia

Full list of author information is available at the end of the article
}

Salmonella enterica is further classified into 6 subspecies (Salmonella enterica subspecies enterica, S. enterica Subspecies salmae, S. enterica Subspecies arizonae, S. enterica Subspecies diarizonae, S. enterica Subspecies hautenae and S. enterica Subspecies indica). Most of the Salmonella serotypes are part of S. enterica subspecies enterica, and over $99 \%$ of human and animal infections are caused by serotypes under this subspecies [3].

Diseases caused by Salmonella represent an important public health problem among the common bacterial 
foodborne pathogens worldwide. It is estimated that globally 93.8 million cases and 155,000 deaths are associated with gastroenteritis due to Salmonella species annually. Of these cases, $85.6 \%$ were estimated to be foodborne [4]. Human salmonellosis has been associated with contaminated food products, mainly those of animal origin such as poultry, beef, pork and dairy products, as well as direct contact with infected animals [5-7].

Various serotypes of Salmonella have been isolated from the feces of apparently healthy dairy cattle. Salmonella in dairy animals may exist as a normal microbiota of the gastrointestinal population, or as a transient member of the gastrointestinal microbial population [8].

All sick, recovered and asymptomatic cattle can shed Salmonella through feces and the organism can survive for a long time in favorable environments outside the host [9]. Fecal shedding of Salmonella can increase intra-herd transmission, accidental spread to other herds, environmental contamination and risk of human infection [10]. Consumption of raw milk, inadequately pasteurized milk, improperly cooked beef from culled dairy cattle, contaminated water and direct animal contact are the major routes of acquiring dairy associated salmonellosis in humans [6].

In Ethiopia, there are large numbers of small-scale peri-urban dairy farms mainly situated close to areas of public residence. Most of these farms are located very close to Addis Ababa, capital city of the country, or reside within the city in a very close proximity with human populations. The consumption of raw milk and its derivatives is common in Ethiopia, posing high risk of infection with dairy-associated foodborne pathogens. Such pathogens include Salmonella spp., Klebsiella spp., Enterobacter spp., and Escherichia coli, which have been identified in milk products in Ethiopia [11]. Gram positive pathogens such as Staphylococcus aureus, Bacillus cereus, Listeria monocytogenes and Enterococcus spp. have also been frequently isolated from milk $[12,13]$.

Occurrence of non-typhoidal Salmonella serotypes commonly infecting humans in dairy cattle, particularly, those stains resistant to antimicrobial agents commonly used in human medicine, are a serious threat to human health. Some multi-drug resistant (MDR) Salmonella outbreaks in humans have been linked to exposure to dairy farms or contaminated dairy products $[6,14]$. Information on the prevalence, serotype distribution and antimicrobial susceptibility of Salmonella in dairy farms is vital to implementation of appropriate strategies to prevent the introduction and spread of the pathogen in the farm as well as to reduce the risk of human salmonellosis. Knowledge on the serotypes circulating in dairy farms would inform scientists/clinicians on the role of dairy cattle as a source of human Salmonella infections. A previous study conducted in Addis Ababa has shown farm level prevalence of $47.8 \%$ and animal level prevalence of $7.7 \%$ [15]. However, this study involved small sample size and the isolates were not serotyped. Given the relative lack of information concerning the prevalence and serotype distribution of Salmonella spp. in dairy farms in Ethiopia, the present study was designed to investigate animal level and herd level fecal prevalence of Salmonella, serotype distribution and antimicrobial resistance profiles of Salmonella in dairy farms in and around Addis Ababa, Ethiopia. It also attempted to investigate the association of farm size, occurrence of diarrhea in the farm and age of animals with prevalence of Salmonella in these dairy farms.

\section{Methods}

Study design, study area and sampling of study animals A cross-sectional study was conducted in Addis Ababa and in five districts of the Oromia region located at the outskirt of Addis Ababa, namely: Sebeta, Barake, Welmera, Sululta and Adaa (Fig. 1). In these areas, the interaction between animal and human population is very high due to high density of the human populations and the large number of peri-urban dairy farming facilities. These areas are the major sources of dairy milk supply to Addis Ababa. Sampling of study herds and animals was conducted from June to December 2013. Study animals were selected from 132 dairy herds (Addis Ababa; $n$ =38; Adaa, $n=12$; Sebeta, $n=21$; Sululta, $n=24$; Welmera; $n=18)$. Inclusion of herd in the sampling was based on representation of the area under study, willingness of the owners, geographical accessibility, and the herd having a minimum of 5 cattle. The largest herd size contained 398 head of cattle. Farms were categorized into small (520 animals in a herd), medium (21-50 animals in a herd) and large (more than 50 animals). Mean herd size of small, medium and large farms was 12.6, 31.7 and 100.4, respectively. In total 1203 fecal samples were collected from healthy as well as diarrheic cattle during the study period. The study design was cross-sectional implying a one point fecal sample collection from a given herd and hence there was no repeated fecal sample collection.

\section{Sample collection, Salmonella isolation and identification}

Fecal samples were collected directly from the rectum using disposable gloves into sterile zippered plastic bags and transported to the Microbiology Laboratory, Aklilu Lemma Institute of Pathobiology, in an ice box within $3-4 \mathrm{~h}$ of collection. Isolation and identification of Salmonella was conducted using conventional methods $[16,17]$. Briefly, $10 \mathrm{~g}$ of feces was pre-enriched in $90 \mathrm{ml}$ of buffered peptone water (BPW) (Becton Dickinson, Sparks, MD) and incubated overnight at $37{ }^{\circ} \mathrm{C}$. A $100 \mu \mathrm{l}$ pre-enriched suspension was added into $9.9 \mathrm{ml}$ of Rappaport-Vassiliadis enrichment Broth (RVB) 


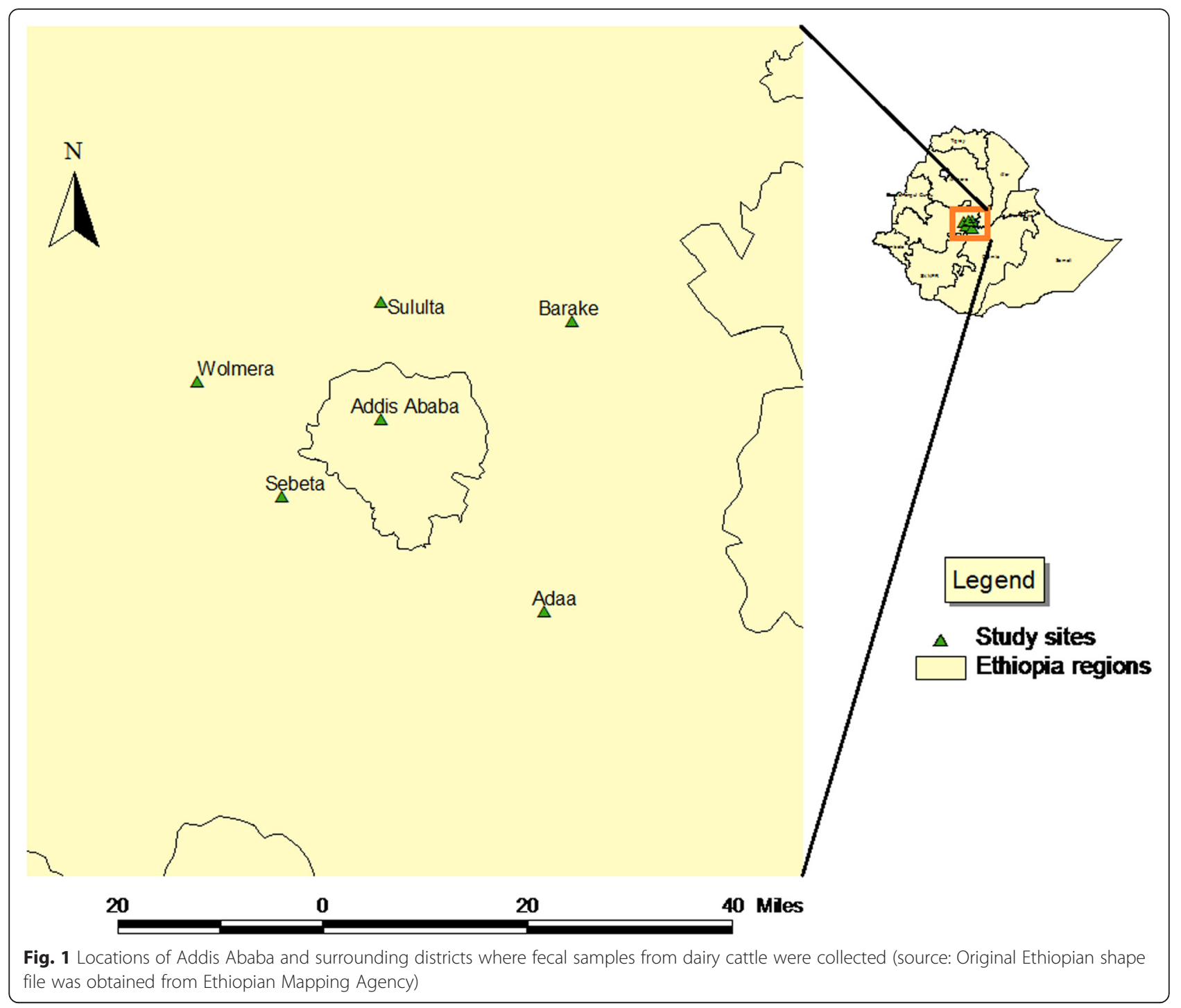

(Oxoid, USA) and incubated at $42{ }^{\circ} \mathrm{C}$ for $24 \mathrm{~h}$. At the same time, $1 \mathrm{ml}$ of suspension was also transferred to $10 \mathrm{ml}$ of Tetrathionate broth (TTB) (Oxoid, USA) and incubated for $24 \mathrm{~h}$ at $37{ }^{\circ} \mathrm{C}$. It was then streaked from both RVB and TTB to Xylose Lysine Tergitol 4 (XLT-4) (Oxoid, USA) selective media and the plates were incubated at $37{ }^{\circ} \mathrm{C}$ for 24 to $48 \mathrm{~h}$. Presumptive Salmonella colonies were further investigated biochemically using Triple Sugar Iron agar, Urea, Citrate and Lysine Iron Agar slants. Those colonies with typical Salmonella biochemical properties were then further confirmed by genus specific PCR [18]. A reference strain of S. Typhimurium (ATCC 14028) was used as a positive control during biochemical analysis and PCR. One confirmed Salmonella isolate from each positive sample was stored at $-80{ }^{\circ} \mathrm{C}$ in $20 \%$ glycerol until further testing.

\section{Data collection}

Information such as herd size, housing condition, types of antimicrobials commonly used in the farm, age, sex of animals and presence of diarrhea in a farm was recorded using a purposively designed questionnaire. A farm was categorized as a diarrheic farm if one or more animals in the herd were diarrheic at the time of sample collection. Collection of data was performed at the time of fecal sample collection from each farm.

\section{Salmonella serotyping and phage typing}

Salmonella isolates were serotyped and phage typed at the World Organization for Animal Health (OIÉ) Reference Laboratory for Salmonellosis of the Public Health Agency of Canada's National Microbiology at Guelph. Serovars were determined by serum agglutination 
according to the White-Kauffmann-Le Minor scheme $[19,20]$, with identification of somatic $(\mathrm{O})$ antigens by slide agglutination tests [21] and flagellar $(\mathrm{H})$ antigens by a microplate agglutination technique [22]. S. Typhimurium isolates were phage typed by the methods developed initially by Callow [23] and extended by Anderson et al. [24] and Rabsch [25] with 30 reference phages obtained directly from the WHO Reference Laboratory for phage typing of Salmonella species at Public Health England or from the same source via Canada's National Microbiology Laboratory at Winnipeg. These typing phages were number 1-35 with discontinued use of phages $9,30,31,33$ and 34. Internal reference strains of phage type 1 (fully susceptible) and phage type 124 (susceptible to only one phage) were included as controls. Isolates that reacted with the phages but did not conform to any recognized phage type were designated atypical (AT), while those that did not react with any of the typing phages were designated untypeable (UT).

\section{Antimicrobial susceptibility testing}

Susceptibility of the isolates to 18 antimicrobials was determined using the Kirby-Bauer disk diffusion method according to the guidelines of the Clinical and Laboratory Standards Institute [26]. The following antimicrobials (Sensi-Discs, Becton, Dickinson and Company, Loveton, USA) and disc potencies $(\mu \mathrm{g})$ were used: amikacin (30), amoxicillin + clavulanic acid (20/10), ampicillin (10), cefoxitin (30), ceftriaxone (30), cephalothin (30), chloramphenicol (30), ciprofloxacin (5), gentamicin (10), kanamycin (30), nalidixic acid (30), neomycin (30), nitrofurantoin (100), streptomycin (10), sulfisoxazole (1000), sulfamethoxazole + trimethoprim (23.75/1.25), trimethoprim (5) and tetracycline (30). The interpretation of the categories of susceptible, intermediate or resistant was based on the CLSI guidelines [26]. For the purpose of analysis, all readings classified as intermediate were considered as resistant unless indicated.

E. coli ATCC 25922 was used as a quality control organism.

\section{Statistical analysis}

The data analysis method that fits to survey data as it is implemented in STATA version 12 was used to estimate prevalence of Salmonella and to investigate its association with pre-specified background characteristics. In animal level analysis, the probability of selecting a given animal from a given herd was considered as a weighting variable. Animal level prevalence of Salmonella was calculated as the weighted percentage of Salmonella culturepositive fecal samples among the total number of animals examined. Herd level prevalence of Salmonella was calculated as the percentage of herds with one or more
Salmonella culture-positive fecal samples among the total number of herds sampled. Association of weighted animal level prevalence and selected background characteristics was assessed using pearson chi-square within survey command of STATA software. Association of herd level Salmonella positivity and pre-specified characteristics was assessed using pearson chi-square. The difference between mean numbers of antimicrobials to which isolates were resistant was compared using a student $t$-test. Results were reported as being statistically significant whenever the $p$-value was less than 0.05 .

\section{Ethics statement}

Ethical clearance for the study was obtained from the National Research Ethics Review Committee, Ethiopia. Informed oral consent was obtained from the farm owners at the time of sample collection.

\section{Results}

\section{Prevalence and risk factors}

Weighted animal level Salmonella prevalence was $2.3 \%$ and at least one Salmonella positive animal was detected in $7.6 \%(10 / 132)$ of the herds examined. There was no significant difference in prevalence of Salmonella between male and female animals. Significant difference in the prevalence of Salmonella was observed across different age groups $(p=0.023)$ and the largest was observed in cattle less than 6 months old. Similarly, animal level prevalence of Salmonella among study sites was significantly different $(p<0.001)$ : highest prevalence was $5 \%$ in Adaa followed by $4.2 \%$ in Addis Ababa and $2.0 \%$ in Sebeta (Table 1). However, herd level prevalence of Salmonella was not significantly different among study sites (Table 2). Diarrhea was detected in 34 of 1203 animals. Three of the diarrheic animals were positive for Salmonella whereas 27 out of 1169 non-diarrheic animals were positive for Salmonella. These 3 Salmonella positive diarrheic animals were a 2 week old calf infected with S.Typhimurium var. Copenhagen on a farm in Adaa district, a 3 month old calf infected with $S$. kentucky in Addis Ababa and a 6 year old cow infected with $S$. Dublin in the Sebeta district. Detection of diarrhea in an animal was significantly associated with animal level Salmonella carriage $(p=0.012)$ (Table 1). Detection of diarrhea in one or more animals in a farm was also significantly associated with herd level prevalence of Salmonella $(p<0.001)$ (Table 2). Out of 255 fecal samples collected from 24 diarrheic herds, 22 were positive for Salmonella whereas, only 8 of the 948 fecal samples collected from 108 non-diarrheic herds were positive for Salmonella. Six of 24 (25\%) of diarrheic herds were positive for Salmonella while only 4 of 108 (3.7 \%) of non-diarrheic herds were positive for Salmonella $(p<0.001)$. 
Table 1 Animal level prevalence of Salmonella and its unadjusted association with selected characteristics

\begin{tabular}{|c|c|c|c|c|}
\hline Characteristics & Categories & Number & Weighted ${ }^{a}$ percent positive for Salmonella & $p$-value \\
\hline \multirow[t]{2}{*}{ Sex } & Male & 101 & 1.4 & 0.483 \\
\hline & Female & 1102 & 2.4 & \\
\hline \multirow[t]{5}{*}{ Age } & $<6$ month & 280 & 4.5 & 0.023 \\
\hline & 6 months -2 years & 162 & 0.0 & \\
\hline & 2 years -5 years & 143 & 2.9 & \\
\hline & 5 years -8 years & 496 & 1.6 & \\
\hline & $\geq 8$ years & 122 & 2.5 & \\
\hline \multirow[t]{6}{*}{ Study site } & Sebeta & 141 & 2.0 & $<0.001$ \\
\hline & Addis Ababa & 319 & 4.2 & \\
\hline & Adaa & 184 & 5.0 & \\
\hline & Barake & 151 & 0.4 & \\
\hline & Welmera & 195 & 0.0 & \\
\hline & Sululta & 213 & 0.2 & \\
\hline \multirow[t]{3}{*}{ Herd Size } & Small [5-20) & 480 & 1.8 & 0.117 \\
\hline & Medium [20-50) & 369 & 2.1 & \\
\hline & Large $[50+$ & 354 & 4.3 & \\
\hline \multirow[t]{2}{*}{ Have diarrhoea } & No & 1169 & 2.1 & 0.012 \\
\hline & Yes & 34 & 9.4 & \\
\hline Overall & & 1203 & 2.3 & \\
\hline
\end{tabular}

${ }^{\mathrm{a}}$ The result was weighted by the probability of selecting animals from its respective farm

There was no significant difference in animal level prevalence of Salmonella among animals from farms of different herd size $(p=0.117)$ (Table 1). However, herd level prevalence of Salmonella was significantly higher in farms with large herd size $(p=0.047)$ (Table 2). All 30 Salmonella isolates were obtained from herds that were kept completely indoors, while none was recovered from farms that allowed their animals to graze outside occasionally or those where cattle were totally outdoors.

\section{Salmonella serotype distribution}

Nine different serotypes were identified (Table 3). S. Typhimurium, grouped with its variant $S$. Typhimurium var. Copenhagen, was the most common $(7 / 30,23.3 \%)$ and was isolated from seven animals on three farms in

Table 2 Herd level prevalence of Salmonella and its unadjusted association with selected farm level characteristics

\begin{tabular}{|c|c|c|c|c|}
\hline Characteristics & Categories & Number of farms studied & Percent positive for Salmonella & $p$-value \\
\hline \multirow[t]{6}{*}{ Study site } & Sebeta & 20 & 5.0 & \multirow[t]{6}{*}{0.372} \\
\hline & Addis Ababa & 38 & 13.2 & \\
\hline & Adaa & 12 & 16.7 & \\
\hline & Barake & 19 & 5.3 & \\
\hline & Welmera & 18 & 0.0 & \\
\hline & Sululta & 25 & 4.0 & \\
\hline \multirow[t]{3}{*}{ Herd Size } & Small [5-20) & 79 & 3.8 & \multirow[t]{3}{*}{0.047} \\
\hline & Medium [20-50) & 33 & 9.1 & \\
\hline & Large $[50+$ & 20 & 20.0 & \\
\hline \multirow[t]{2}{*}{ Farm diarrhoea status } & Diarrheic & 24 & 25.0 & \multirow[t]{2}{*}{$<0.001$} \\
\hline & Non-diarrheic & 108 & 3.7 & \\
\hline Overall & & 132 & 7.6 & \\
\hline
\end{tabular}


Table 3 Salmonella serotype distribution and number and percent of intermediate and resistant isolates to antimicrobial agents

\begin{tabular}{|c|c|c|c|c|c|c|c|c|c|c|c|c|c|c|c|c|c|c|c|c|c|c|c|c|c|c|c|}
\hline \multirow[t]{3}{*}{ Serotype } & \multirow[t]{3}{*}{ Number } & \multicolumn{26}{|c|}{ No. of intermediately resistant and resistant isolates } \\
\hline & & \multicolumn{2}{|c|}{ Amp } & \multicolumn{2}{|l|}{ Amc } & \multicolumn{2}{|l|}{ Cf } & \multicolumn{2}{|l|}{ Cip } & \multicolumn{2}{|l|}{$\mathrm{Gm}$} & \multicolumn{2}{|l|}{ K } & \multicolumn{2}{|c|}{ Tmp } & \multicolumn{2}{|l|}{$\mathrm{Te}$} & \multicolumn{2}{|l|}{ Su } & \multicolumn{2}{|l|}{ 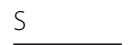 } & \multicolumn{2}{|c|}{ Nitro } & \multicolumn{2}{|l|}{$\mathrm{Na}$} & \multicolumn{2}{|l|}{$\mathrm{N}$} \\
\hline & & I & $\mathrm{R}$ & I & $\mathrm{R}$ & I & $\mathrm{R}$ & I & $\mathrm{R}$ & I & $\mathrm{R}$ & I & $\mathrm{R}$ & I & $\mathrm{R}$ & I & $\mathrm{R}$ & I & $\mathrm{R}$ & I & $\mathrm{R}$ & I & $\mathrm{R}$ & I & $\mathrm{R}$ & I & $\mathrm{R}$ \\
\hline Aberdeen & 1 & - & - & - & - & - & - & 1 & - & - & - & 1 & - & - & - & 1 & - & 1 & - & 1 & - & - & 1 & 1 & - & 1 & - \\
\hline Dublin & 3 & - & - & - & & 2 & - & - & - & - & - & - & - & - & - & - & - & 1 & - & 3 & - & - & - & - & - & - & - \\
\hline I:6,7,14:-:I,w & 1 & - & 1 & - & 1 & - & 1 & 1 & - & - & - & - & - & - & - & 1 & - & - & - & 1 & - & - & 1 & 1 & - & - & - \\
\hline Kentucky & 5 & - & 5 & 2 & 3 & - & 5 & - & 5 & - & 5 & 4 & - & - & 1 & - & 5 & - & 5 & - & 5 & 4 & 1 & - & 5 & - & 2 \\
\hline LivingstoneVar.14+ & 1 & - & - & - & - & - & - & 1 & - & - & - & - & - & - & - & - & - & - & - & - & - & - & - & - & 1 & - & - \\
\hline Mikawasima & 1 & - & - & - & - & - & - & - & - & - & - & - & - & - & - & - & - & 1 & - & - & & 1 & - & - & - & - & - \\
\hline Saintpaul & 6 & 1 & - & - & - & 1 & - & - & - & - & - & 4 & - & - & - & 4 & - & 3 & 2 & 5 & 1 & 2 & 3 & - & - & 3 & - \\
\hline Typhimurium & 7 & - & - & - & & 2 & - & - & - & - & - & 3 & - & - & - & 4 & - & 3 & - & 7 & - & 1 & 1 & 1 & - & 1 & - \\
\hline Virchow & 5 & - & 3 & 3 & - & - & 3 & 1 & - & 1 & 1 & 1 & - & - & - & - & 1 & 1 & 1 & 1 & 2 & 1 & 3 & - & 2 & - & - \\
\hline Total & 30 & 1 & 9 & 5 & 4 & 5 & 9 & 4 & 5 & 1 & 6 & 13 & - & - & - & 10 & 6 & 10 & 8 & 18 & 8 & 9 & 10 & 3 & 8 & 5 & 2 \\
\hline$\% R$ & & 3.3 & 30 & 16.7 & 13.3 & 16.7 & 30 & 13.3 & 16.7 & 3.3 & 20 & 43.3 & - & - & 3.3 & 33.3 & 20 & 33.3 & 26.7 & 60 & 26.7 & 30 & 33.3 & 10 & 26.7 & 16.7 & 6.7 \\
\hline$\%(I+R)$ & & 33.3 & & 30 & & 46.7 & & 30 & & 23.3 & & 43.3 & & 3.3 & & 53.3 & & 60 & & 86.7 & & 63.3 & & 36.7 & & 23.3 & \\
\hline
\end{tabular}

Since all isolates were susceptible to Amikacin, Chloramphenicol, Cefoxitin, Ceftriaxone and Sulfamethoxazole + Trimethoprim, they were not included in the table

Amp Ampicillin, Amc Amoxicillin and clavulanic acid, Cf Cephalothin, Cip Ciprofloxacin, Gm Gentamicin, K Kanamycin, Tmp Trimethoprim, Te Tetracycline, Su Sulfisoxazole, S Streptomycin, Nitro Nitrofurantoin, Na Nalidixic acid, $N$ Neomycin, I Intermediate, $R$ Resistant 
three study sites (Adaa, Sululta and Barake districts). $S$. Saintpaul (6, $20 \%$ ) was isolated only from a single farm in the Adaa district, $S$. Kentucky $(5,16.7 \%)$, and $S$. Virchow $(5,16.7 \%)$ were isolated from five animals each in two different farms in Addis Ababa, while S. Dublin (3, $10 \%)$ and one isolate $(1,3.3 \%)$ of $S$. Livingstone var.14 +, S. I: 6, 7, 14:-: I,w, S. Mikawasima and S. Aberdeen were isolated from one animal on five different farms. Two different serotypes were isolated from two farms in the present study (Table 4).

\section{Antimicrobial resistance}

The common antimicrobials used in the farms were oxytetracycline, penicillin + streptomycin, and sulfonamide in $94.6,81.8$ and $13.6 \%$ of the farms, respectively. Resistance patterns of the isolates are shown in Table 4. All isolates were resistant to at least one of the 18 antimicrobials tested. Twenty-six (86.7 \%), 19 (63.3 \%), 18 (60\%), $16(53.3 \%)$ of the isolates were resistant to streptomycin, nitrofurantoin, sulfisoxazole and tetracycline, respectively. Resistance to two or more antimicrobials was recorded in $90 \%$ of the isolates, while resistance to 3 or more antimicrobials was detected in $21(70 \%)$ of the isolates. MDR to 7 or more antimicrobials were detected in $11(36.7 \%)$ of the isolates. The five $S$. Kentucky isolates were resistant to 10-13 antimicrobials (Table 4). One isolate ( $S$. Kentucky) from a farm in Addis Ababa was resistant to 13 out of 18 antimicrobials tested. All isolates were susceptible to amikacin, chloramphenicol, cefoxitin, ceftriaxone and sulfamethoxazole + trimethoprim.

There was a statistically significant difference in the rate of occurrence of MDR between isolates obtained from dairy farms in Addis Ababa and outside of the city limits of Addis Ababa. The mean \pm standard error of mean (SEM) number of antimicrobials to which isolates obtained from Addis Ababa were resistant was $7.23 \pm$ 1.32, while isolates obtained outside of Addis Ababa were resistant to $4 \pm 0.62$ antimicrobials $(p=0.01)$. Resistance to first line antimicrobial agents in human medicine for treatment of Salmonella like beta-lactam and quinolones was also more common in isolates obtained from Addis Ababa. The extent of MDR varied with the serotype, as the overall MDR was more common in $S$. Kentucky, $S$. Virchow and $S$. Saintpaul compared to strains from other serotypes. Interestingly, all of the 5 Kentucky strains were resistant to nalidixic acid and ciprofloxacin (Table 4).

\section{Discussion}

Food animals are the primary sources for transmitting non-typhoidal Salmonella to humans [27]. Outbreaks of salmonellosis in humans has been linked to improperly pasteurized dairy products, undercooked beef, water runoff from farms, and direct animal or fecal contact [28]. In the current study, farm level prevalence of Salmonella was $7.6 \%$ and individual animal level prevalence was $2.3 \%$, which is much lower than the previous studies in the USA, where $31 \%$ of dairy farms had at least one cow shedding Salmonella in feces and $7.3 \%$ of individual animals were shedding [29]. It is also much lower than a previous study conducted in Addis Ababa [15] that reported farm level fecal prevalence of $47.8 \%$ and individual animal level prevalence of $7.7 \%$. A study on slaughtered cattle in Addis Ababa recovered Salmonella from $7.1 \%$ of apparently healthy animals [30]. Recent study in Jordan showed $23 \%$ and $4 \%$ of herd level and individual animal level prevalence of Salmonella in dairy farms, respectively, which is also higher than our finding [31]. This difference could be due to differences in the Salmonella isolation protocol employed in each study, seasonal variation in Salmonella shedding of animals as well as other factors such as herd size and age composition [28, 29]. Most of the farms in the current study had small herd size. Moreover, animals of all age groups in the farm were sampled in the current study unlike the other two studies [15, 29] which involved only lactating cows.

This study also showed that Salmonella shedding was common in farms that keep animals completely indoors while none was detected in those that occasionally graze outside or are totally outdoors. Similarly, higher prevalence of Salmonella was reported in swine kept indoors than those kept outdoors [32]. This probably is due to free cycling of Salmonella between animals in a limited host environment once the pathogen gets access to the farm in animals kept indoors. The fact that the use of processed feed is more common in animals kept indoors than those kept outdoors might also suggest the possibility of indoor kept animals being infected with Salmonella from contaminated animal feed. A previous study has also shown livestock waste generated by animals consuming a diet principally composed of grass were less likely to harbor Salmonella spp. [33].

In this study, the larger the herd size, the higher the probability of having Salmonella positive animals in the farm, which is in agreement with previous reports [3437]. This could be due to overcrowding of animals in the larger herds, especially those housed indoors, increasing animal to animal contact which enhances transmission of pathogens within the herd. Moreover, the larger the number of animals in the herd, the higher the probability of having a few weak and stressed animals, which increases the likelihood of continuous shedding of Salmonella from these cattle. Asymptomatic carrier cattle have been reported to shed Salmonella for up to 18 months [38]. Additionally, in the absence of mechanized feeding and milking systems in 
Table 4 Salmonella serotypes isolated from dairy cattle in various study sites and their antimicrobial resistance pattern

\begin{tabular}{|c|c|c|c|c|c|}
\hline \multirow[t]{2}{*}{ Number } & \multirow[t]{2}{*}{ Study site } & \multirow{2}{*}{$\begin{array}{l}\text { Farm } \\
\text { Code }\end{array}$} & \multirow[t]{2}{*}{ Serotype } & \multicolumn{2}{|l|}{ R-pattern } \\
\hline & & & & Intermediate & Resistant \\
\hline 1 & Adaa & DZC -03 & Aberdeen & CipKTeSuSNaN & Nitros \\
\hline 2 & Adaa & DZC -03 & Saintpaul & NitroSuS & - \\
\hline 3 & Adaa & DZC -03 & Saintpaul & TeSus & Nitro \\
\hline 4 & Adaa & DZC -03 & Saintpaul & AmpCfKTeSNaN & SuNitro \\
\hline 5 & Adaa & DZC -03 & Saintpaul & KTeN & SuSNitro \\
\hline 6 & Adaa & DZC -03 & Saintpaul & KS & - \\
\hline 7 & Adaa & DZC -03 & Saintpaul & NitroKTeSuSN & \\
\hline 8 & Adaa & DZC-06 & Typhimurium var. copehagen PT 193 & CfKS & - \\
\hline 9 & Adaa & DZC-06 & Typhimurium var. copehagen PT 193 & CfTeSuS & - \\
\hline 10 & Adaa & DZC-06 & Typhimurium var. copehagen PT U285 & KTeSuSNitroNaN & - \\
\hline 11 & Adaa & DZC-06 & Typhimurium var. copehagen PT193 & Tes & - \\
\hline 12 & Addis Ababa & AAC-25 & $\mathrm{I}: 6,7,14:-\mathrm{I}, \mathrm{W}$ & CipTeSNa & AmpAmcCfNitro \\
\hline 13 & Addis Ababa & AAC-38 & Kentucky & KNitro & AmpAmcCfCipGmTeSuSNa \\
\hline 14 & Addis Ababa & AAC-25 & Kentucky & Nitro & AmpAmcCfCipGmTeSuSNa \\
\hline 15 & Addis Ababa & AAC-38 & Kentucky & KNitro & AmpAmcCfCipGmTeSuSNa \\
\hline 16 & Addis Ababa & AAC-38 & Kentucky & AmcKNitro & AmpCfCipGmTeSuSNaN \\
\hline 17 & Addis Ababa & AAC-38 & Kentucky & AmcK & AmpCfCipGmTmpTeSuSNitroNaN \\
\hline 18 & Addis Ababa & AAC-25 & Livingstone Var.14+ & Cip & $\mathrm{Na}$ \\
\hline 19 & Addis Ababa & AAC-09 & Mikawasima & SuNitro & - \\
\hline 20 & Addis Ababa & AAC-23 & Virchow & Amc & AmpCf \\
\hline 21 & Addis Ababa & AAC-23 & Virchow & AmcK & AmpCfCipGmTeSuSNitroNa \\
\hline 22 & Addis Ababa & AAC-23 & Virchow & AmcSu & AmpCfSNitroNa \\
\hline 23 & Addis Ababa & AAC-23 & Virchow & GmSNitro & - \\
\hline 24 & Addis Ababa & AAC-24 & Virchow & - & Nitro \\
\hline 25 & Barake & BAR- 18 & Typhimurium PT Atypical & KSuS & Nitro \\
\hline 26 & Barake & BAR- 18 & Typhimurium PT 67 & S & - \\
\hline 27 & Sebeta & SC-04 & Dublin & $\mathrm{Cf}, \mathrm{S}$ & - \\
\hline 28 & Sebeta & SC-04 & Dublin & CfSuS & - \\
\hline 29 & Sebeta & SC-04 & Dublin & S & - \\
\hline 30 & Sululta & Suc-07 & Typhimurium var. copehagen PT Atypical & Tes & - \\
\hline
\end{tabular}

PT Phagetype, Amp Ampicillin, Amc Amoxicillin and clavulanic acid, Cf Cephalothin, Cip Ciprofloxacin, Gm Gentamicin, K Kanamycin, Tmp Trimethoprim, Te Tetracycline, Su Sulfisoxazole, S Streptomycin, Nitro Nitrofurantoin, Na Nalidixic acid, $N$ Neomycin

Ethiopia, several animal attendants are involved in daily activities of the large farms with the possibility of serving as a source of dissemination among individual animals in a farm. Contrary to the above findings, another study has reported that there is no association of herd size and Salmonella shedding [29].

The strong association of individual animal and herd level prevalence of Salmonella with detection of diarrhea in one or more animals suggests that Salmonella is one of the causes of diarrhea in dairy cattle in the study population. Detection of more Salmonella from diarrheic as well as non-diarrheic cattle in farms with one or more diarrheic animal in the herd might be due to the presence of carrier animals shedding Salmonella to other animals without showing clinical manifestations post infection or after recovery from clinical salmonellosis [39].

The higher Salmonella recovery rate in young animals in the current study is presumably due to the lack of an adequate adaptive immune response in the young calves compared to adult animals. Also, co-infection with multiple enteric pathogens is common in calves and may compromise their immune system. In addition, relative lack of protective microflora in calves may also predispose them to pathogenic organisms [37]. A previous study has similarly reported an inverse relationship of calf age and the prevalence of Salmonella [40]. 
The dominant serotypes isolated from dairy cattle in the current study, S. Typhimurium, S. Saintpaul, S. Virchow and $S$. Kentucky, are among the common causes of non-typhoidal salmonellosis in humans [41-43]. There is no previous report in Ethiopia showing serotype distribution of Salmonella in dairy cattle. The top three serotypes in slaughtered cattle in Addis Ababa were $S$. Mishmarhaemek, $S$. Typhimurium and $S$. Enteritidis [30]. In another study conducted in north Ethiopia in slaughtered cattle, $S$. Typhimurium and $S$. Newport were the two dominant serotypes recovered [44].

The observed high resistance to streptomycin and tetracycline is not surprising since these antimicrobials are commonly used in most of the farms for management of bacterial infections. Similar high resistance rates were reported to streptomycin $(77 \%)$ and tetracycline $(65.5 \%)$ in Salmonella isolates obtained from different food animals from Ethiopia [45]. Another study also reported 75 and $46.9 \%$ resistance to streptomycin and tetracycline in Salmonella isolated from different food items and personnel in Addis Ababa [46]. Though nitrofurantoin and sulfonamide were less commonly used in the farms during the study period, large proportion of isolates were resistant to these agents. This is probably due to the fact that these antimicrobials had been used in the animal health sector for a long time in the country and Salmonella had already developed resistance. A previous study conducted in Addis Ababa [15] showed $83 \%$ of Salmonella isolates from dairy farms to be resistant to 2 or more antimicrobials out of 10 antimicrobials tested. Unlike the previous study [15] that reported $100 \%$ resistance to ampicillin, in the current study, only $33.3 \%$ of the isolates exhibited resistance to ampicillin. However, most of the isolates obtained from farms in Addis Ababa were resistant to ampicillin.

Resistance to ciprofloxacin was not reported in the previous study [15], but in the current study, $30 \%$ of the isolates were resistant to ciprofloxacin. Despite detection of resistance to ciprofloxacin and nalidixic acid in the current study, from our interview with farm owners during sampling, none of the farms was using ciprofloxacin or other quinolone antimicrobials to treat their dairy cattle, and use of quinolones is not a regular practice in veterinary medicine in Ethiopia. However, a similar high percentage of resistance to ciprofloxacin was observed in $S$. Kentucky isolates carrying Salmonella Genomic Island K (SGI1-K) collected during 2000-2008 from meat of swine, cattle and poultry [45]. Also, recently isolated $S$. Kentucky strains from diarrheic patients in Addis Ababa were resistant to several antimicrobials including ciprofloxacin [47]. MDR S. Kentucky belonging to a single clone resistant to quinolones and carrying SGI1-K has been reported from European travelers returning from different African and Asian countries [48]. This occurrence of MDR S. Kentucky in both humans and animals in the region might be due to this specific clone widely circulating in Africa.

The high MDR in Salmonella from dairy cattle is alarming. The incidence of MDR in Salmonella has increased in the last few decades globally [49]. Infection of humans with MDR strains of Salmonella has been reported to be associated with increased burden of morbidity, extended hospitalization, increased risk of invasive illness and increased mortality, compared to those infected with susceptible strains [50-52]. In fact, the increase in MDR observed in Salmonella isolates from dairy farms in Addis Ababa compared to those out of Addis Ababa could be due to greater availability of antimicrobial agents and extensive use of antimicrobials in both animals and humans, fostered by a highly populated city where animals and humans live in close proximity.

\section{Conclusion}

The occurrence of MDR Salmonella serotypes that commonly cause human salmonellosis in dairy herds residing in close proximity with human populations warrants the need for strict biosecurity and intervention strategies to control these Salmonella isolates in dairy farms and to protect human and animal health. Paramount is the resistance to ciprofloxacin, which is of great concern as this antimicrobial is among the last options for treatment of complicated non-typhoidal salmonellosis in humans.

\section{Abbreviations}

BPW: buffered peptone water; MDR: multi-drug resistance; PT: phage type; RVB: Rappaport-Vassiliadis broth; SEM: standard error of the mean;

TTB: tetrathionate broth; WHO: World Health Organization.

\section{Competing interests \\ The authors declare that they have no competing interests.}

\section{Authors' contributions}

$T E$, EE, WG, JSG and DA, participated in conception of the study and review of the draft manuscript. TE was involved in sample collection laboratory investigation and preparation of the draft manuscript. HA participated in laboratory work. RPJ was involved in serotyping, and phage typing of the isolates as well as preparation of the manuscript. GM participated in data analysis. All authors read and approved the final manuscript.

\section{Acknowledgments}

This study was financially supported by The National Institutes of Health (NIH) Fogarty International Center (grant 043TW008650) to W.A.G.J.S.G. and WHO/AGISAR to T.E. We are grateful to Linda Cole, Shaun Kernaghan, Ketna Mistry, Ann Perets and Betty Wilkie of the Public Health Agency of Canada, National Microbiology Laboratory at Guelph for serotyping and phagetyping of the Salmonella isolates. Technical assistance of Mr. Nega Nigusie during sample collection is highly appreciated.

\section{Author details}

Aklilu Lemma Institute of Pathobiology, Addis Ababa University, P.O. Box 1176, Addis Ababa, Ethiopia. ${ }^{2}$ Department of Pharmacology and Clinical Pharmacy, School of Pharmacy, College of Health Sciences, Addis Ababa University, Churchill Avenue, P.O. Box 1176, Addis Ababa, Ethiopia.

${ }^{3}$ Department of Veterinary Preventive Medicine, The Ohio State University, 1920 Coffey Rd., Columbus, OH 43210, USA. ${ }^{4}$ Department of Microbiology, 
Immunology \& Parasitology, School of Medicine, College of Health Sciences, Addis Ababa University, Churchill Avenue, P.O. Box 9086 Addis Ababa, Ethiopia. ${ }^{5}$ Laboratory for Foodborne Zoonoses, 110 Stone Road West, Guelph, ON N1G 3W4, Canada. ${ }^{6}$ Department of Microbial Infection and Immunity, Center for Microbial Interface Biology, The Ohio State University, Biomedical Research Tower, 460 West 12th, Columbus, OH 43210-1214, USA.

Received: 20 July 2015 Accepted: 9 February 2016

Published online: 16 February 2016

\section{References}

1. Guibourdenche M, Roggentin P, Mikoleit M, Fields PI, Bockemühl J, Grimont PA, Weill FX. Supplement 2003-2007 (No. 47) to the White-Kauffmann-Le Minor scheme. Res Microbiol. 2010;161(1):26-9.

2. Hoelzer K, Moreno Switt Al, Wiedmann M. Animal contact as a source of human non-typhoidal salmonellosis. Vet Res. 2011;42:34.

3. Uzzau S, Brown DJ, Wallis T, Rubino S, Leori G, Bernard S, Casadesús J, Platt DJ, Olsen JE. Host adapted serotypes of Salmonella enterica. Epidemiol Infect. 2000;125(2):229-55.

4. Majowicz SE, Musto J, Scallan E, Angulo FJ, Kirk M, O'Brien SJ, Jones TF, Fazil A, Hoekstra RM, Studies ICoEDBol. The global burden of nontyphoidal Salmonella gastroenteritis. Clin Infect Dis. 2010;50(6):882-9.

5. Bouchrif B, Le Hello S, Pardos M, Karraouan B, Perrier-Gros-Claude JD, Ennaji MM, Timinouni M, Weill FX. Ceftazidime-resistant Salmonella enterica, Morocco. Emerg Infect Dis. 2009;15(10):1693-5.

6. Fey PD, Safranek TJ, Rupp ME, Dunne EF, Ribot E, Iwen PC, Bradford PA, Angulo FJ, Hinrichs SH. Ceftriaxone-resistant salmonella infection acquired by a child from cattle. N Engl J Med. 2000;342(17):1242-9.

7. Bartholomew ML, Heffernan RT, Wright JG, Klos RF, Monson T, Khan S, Trees E, Sabol A, Willems RA, Flynn R, et al. Multistate outbreak of Salmonella enterica serotype enteritidis infection associated with pet guinea pigs. Vector Borne Zoonotic Dis. 2014;14(6):414-21.

8. Roy R, Higgins R, Fortin M, Tardif S. Salmonella give infection in 2 dairy herds. Can Vet J. 2001;42(6):468-70.

9. Wray C, Wary A. Salmonella in Domestic Animals. Wallingford: CABI Pub.; 2000.

10. Wells SJ, Fedorka-Cray PJ, Dargatz DA, Ferris K, Green A. Fecal shedding of Salmonella spp. by dairy cows on farm and at cull cow markets. J Food Prot. 2001;64(1):3-11.

11. Yilma Z, Faye B, Loiseau G. Occurrence and distribution of species of Enterobacteriaceae in selected Ethiopian traditional dairy products: a contribution to epidemiology. Food Control. 2007;18:1397-404.

12. Tigabu E, Asrat D, Kassa T, Sinmegn T, Molla B, Gebreyes W. Assessment of risk factors in milk contamination with Staphylococcus aureus in Urban and Peri-Urban small-holder dairy farming in Central Ethiopia. Zoonoses Public Health. 2015;62:637.

13. Adugna M, Asresie A. A review on microbiological quality of Ethiopian raw bovine milk. Food Sci Qual Manage. 2015;35:17-34

14. Gupta A, Fontana J, Crowe C, Bolstorff B, Stout A, Van Duyne S, Hoekstra MP, Whichard JM, Barrett TJ, Angulo FJ, et al. Emergence of multidrugresistant Salmonella enterica serotype Newport infections resistant to expanded-spectrum cephalosporins in the United States. J Infect Dis. 2003; 188(11):1707-16

15. Addis Z, Kebede N, Worku Z, Gezahegn H, Yirsaw A, Kassa T. Prevalence and antimicrobial resistance of Salmonella isolated from lactating cows and in contact humans in dairy farms of Addis Ababa: a cross sectional study. BMC Infect Dis. 2011;11:222.

16. Molla B, Sterman A, Mathews J, Artuso-Ponte V, Abley M, Farmer W, RajalaSchultz P, Morrow WE, Gebreyes WA. Salmonella enterica in commercial swine feed and subsequent isolation of phenotypically and genotypically related strains from fecal samples. Appl Environ Microbiol. 2010;76(21):7188-93.

17. WHO. WHO Global Foodborne Infections Network Laboratory Protocol. In: Isolation of Salmonella spp. From Food and Animal Feace. 5th ed. 2010.

18. Cohen ND, Neibergs HL, McGruder ED, Whitford HW, Behle RW, Ray PM, Hargis BM. Genus-specific detection of salmonellae using the polymerase chain reaction (PCR). J Vet Diagn Invest. 1993;5(3):368-71.

19. Grimont PAD, Weill FX. Antigenic formulae of the Salmonella Serovars. 9th ed. Paris: Institut Pasteur; 2007.

20. Issenhuth-Jeanjean S, Roggentin P, Mikoleit M, Guibourdenche M, de Pinna E, Nair S, Fields PI, Weill FX. Supplement 2008-2010 (no. 48) to the WhiteKauffmann-Le Minor scheme. Res Microbiol. 2014;165(7):526-30.
21. Ewing. Serological Identificaiton of Salmonella. 1986

22. Shipp CR, Rowe B. A mechanised microtechnique for salmonella serotyping. J Clin Pathol. 1980;33(6):595-7.

23. Callow BR. A new phage-typing scheme for Salmonella typhi-murium. J Hyg (Lond). 1959;57:346-59.

24. Anderson ES, Ward LR, Saxe MJ, de Sa JD. Bacteriophage-typing designations of Salmonella typhimurium. J Hyg (Lond). 1977;78(2):297-300.

25. Rabsch W. Salmonella typhimurium phage typing for pathogens. Methods Mol Biol. 2007:394:177-211.

26. CLSI. Performance Standards for Antimicrobial Susceptibility Testing; Twenty-Third Informational SupplementM100-S23, vol. 33. 2013.

27. Branham LA, Carr MA, Scott CB, Callaway TR. E. coli 0157 and Salmonella spp. in white-tailed deer and livestock. Curr Issues Intest Microbiol. 2005; 6(2):25-9.

28. Callaway TR, Edrington TS, Anderson RC, Byrd JA, Nisbet DJ. Gastrointestinal microbial ecology and the safety of our food supply as related to Salmonella. J Anim Sci. 2008:86(14 Suppl):E163-72

29. Fossler CP, Wells SJ, Kaneene JB, Ruegg PL, Warnick LD, Bender JB, Eberly LE, Godden SM, Halbert LW. Herd-level factors associated with isolation of Salmonella in a multi-state study of conventional and organic dairy farms I. Salmonella shedding in cows. Prev Vet Med. 2005;70(3-4):257-77.

30. Alemayehu D, Molla B, Muckle A. Prevalence and antimicrobial resistance pattern of Salmonella isolates from apparently healthy slaughtered cattle in Ethiopia. Trop Anim Health Prod. 2003;35(4):309-19.

31. Tarazi YH, Abo-Shehada MN. Herd- and individual-level prevalences of and risk factors for Salmonella spp. fecal shedding in dairy farms in Al-Dhulail Valley, Jordan. Trop Anim Health Prod. 2015;47(7):1241-8.

32. Bonde M, Sørensen JT. Salmonella infection level in Danish indoor and outdoor pig production systems measured by antbodies in meat juice and faecal shedding on-farm and at slaughter. Anim Health Anim Welf Biosecur Proc. 2007;2:729-34.

33. Hutchison ML, Walters LD, Avery SM, Munro F, Moore A. Analyses of livestock production, waste storage, and pathogen levels and prevalences in farm manures. Appl Environ Microbiol. 2005;71(3):1231-6.

34. Warnick LD, Kanistanon K, McDonough PL, Power L. Effect of previous antimicrobial treatment on fecal shedding of Salmonella enterica subsp. enterica serogroup B in New York dairy herds with recent clinical salmonellosis. Prev Vet Med. 2003;56(4):285-97.

35. Davison HC, Sayers AR, Smith RP, Pascoe SJ, Davies RH, Weaver JP, Evans SJ. Risk factors associated with the salmonella status of dairy farms in England and Wales. Vet Rec. 2006;159(26):871-80.

36. Blau DM, McCluskey BJ, Ladely SR, Dargatz DA, Fedorka-Cray PJ, Ferris KE, Headrick ML. Salmonella in dairy operations in the United States: prevalence and antimicrobial drug susceptibility. J Food Prot. 2005;68(4):696-702.

37. Cummings KJ, Warnick LD, Alexander KA, Cripps CJ, Gröhn YT, McDonough $\mathrm{PL}$, Nydam DV, Reed KE. The incidence of salmonellosis among dairy herds in the northeastern United States. J Dairy Sci. 2009;92(8):3766-74.

38. Evans S, Davies R. Case control study of multiple-resistant Salmonella typhimurium DT104 infection of cattle in Great Britain. Vet Rec. 1996; 139(23):557-8

39. Cho Yl, Yoon KJ. An overview of calf diarrhea - infectious etiology, diagnosis, and intervention. J Vet Sci. 2014;15(1):1-17.

40. Berge AC, Moore DA, Sischo WM. Prevalence and antimicrobial resistance patterns of Salmonella enterica in preweaned calves from dairies and calf ranches. Am J Vet Res. 2006;67(9):1580-8.

41. Okoro CK, Kingsley RA, Connor TR, Harris SR, Parry CM, Al-Mashhadani MN,

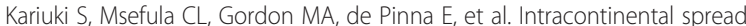
of human invasive Salmonella Typhimurium pathovariants in sub-Saharan Africa. Nat Genet. 2012:44(11):1215-21.

42. Bonalli M, Stephan R, Käppeli U, Cernela N, Adank L, Hächler H. Salmonella enterica serotype Virchow associated with human infections in Switzerland: 2004-2009. BMC Infect Dis. 2011;11:49.

43. Barton Behravesh C, Mody RK, Jungk J, Gaul L, Redd JT, Chen S, Cosgrove S, Hedican E, Sweat D, Chávez-Hauser L, et al. 2008 outbreak of Salmonella Saintpaul infections associated with raw produce. N Engl J Med. 2011; 364(10):918-27.

44. Alemu S, Zewde BM. Prevalence and antimicrobial resistance profiles of Salmonella enterica serovars isolated from slaughtered cattle in Bahir Dar. Ethiopia Trop Anim Health Prod. 2012;44(3):595-600.

45. Eguale T, Marshall J, Molla B, Bhatiya A, Gebreyes WA, Engidawork E, Asrat $D$, Gunn JS. Association of multicellular behaviour and drug resistance in 
Salmonella enterica serovars isolated from animals and humans in Ethiopia. J Appl Microbiol. 2014;117(4):961-71.

46. Endrias Z, Poppe C. Antimicrobial resistance pattern of Salmonella serotypesisolated from food items and personnel in AddisAbaba, Ethiopia. Trop Anim Prod. 2009;41:241-9.

47. Equale T, Gebreyes WA, Asrat D, Alemayehu H, Gunn JS, Engidawork E. Non-typhoidal Salmonella serotypes, antimicrobial resistance and coinfection with parasites among patients with diarrhea and other gastrointestinal complaints in Addis Ababa, Ethiopia. BMC Infect Dis. 2015; 15:497.

48. Le Hello S, Hendriksen RS, Doublet B, Fisher I, Nielsen EM, Whichard JM, Bouchrif B, Fashae K, Granier SA, Jourdan-Da Silva N, et al. International spread of an epidemic population of Salmonella enterica serotype Kentucky ST198 resistant to ciprofloxacin. J Infect Dis. 2011;204(5):675-84.

49. Wright JG, Tengelsen LA, Smith KE, Bender JB, Frank RK, Grendon JH, Rice DH, Thiessen AM, Gilbertson CJ, Sivapalasingam S, et al. Multidrug-resistant Salmonella Typhimurium in four animal facilities. Emerg Infect Dis. 2005; 11(8):1235-41

50. Martin LJ, Fyfe M, Doré K, Buxton JA, Pollari F, Henry B, Middleton D, Ahmed $R$, Jamieson F, Ciebin B, et al. Increased burden of illness associated with antimicrobial-resistant Salmonella enterica serotype typhimurium infections. J Infect Dis. 2004:189(3):377-84.

51. Helms M, Simonsen J, Molbak K. Quinolone resistance is associated with increased risk of invasive illness or death during infection with Salmonella serotype Typhimurium. J Infect Dis. 2004;190(9):1652-4.

52. Varma JK, Molbak K, Barrett TJ, Beebe JL, Jones TF, Rabatsky-Ehr T, Smith KE, Vugia DJ, Chang HG, Angulo FJ. Antimicrobial-resistant nontyphoidal Salmonella is associated with excess bloodstream infections and hospitalizations. J Infect Dis. 2005;191(4):554-61.

\section{Submit your next manuscript to BioMed Central and we will help you at every step:}

- We accept pre-submission inquiries

- Our selector tool helps you to find the most relevant journal

- We provide round the clock customer support

- Convenient online submission

- Thorough peer review

- Inclusion in PubMed and all major indexing services

- Maximum visibility for your research

Submit your manuscript at www.biomedcentral.com/submit 